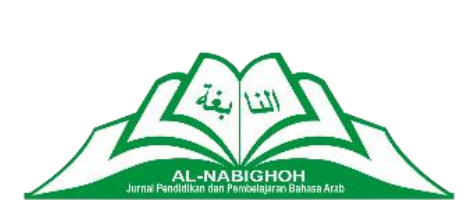

\title{
PERGESERAN TERJEMAHAN PADA TEKS HADIS DALAM DUA VERSI TERJEMAHAN KITAB TAZKIYATUN NUFUS WA TARBIYATUHA
}

\author{
Muhammad Yunus Anis ${ }^{1}$, Hasna Nurul Istiqomah ${ }^{2}$
}

1,2 Universitas Sebelas Maret, Indonesia

\section{Article Info}

\section{Article History:}

Received: June 2021

Revised: October 2021

Accepted: December 2021

Published: December 2021

\section{*Corresponding Author:}

Name:

Muhammad Yunus Anis

Email:

yunus_678@staff.uns.ac.id

\section{Abstract}

This research analyses the translation shift of the hadis text in two versions of the translation of the tazkiyatun nufūs wa tarbiyatuhā works by Ibnu Rajab, Ibnu Qayyim and Imam Al-Ghazali, which Imtihan Asy-Syafi'i has translated as the first target text and which Umar Mujtahid has translated as the second target text. The translation shift in this study is divided into two. namely, shift in form and meaning. This translation shift occurred on the words. The purpose of this study is to describe the translation shift used by the translator in translating the tazkiyatun nufūs wa tarbiyatuhā book. The method used in this research is qualitative descriptive method. The source of the data in the form of book tazkiyatun nufūs wa tarbiyatuhā and two versions of its translation. The data analysis was done gradually. First, collecting the data and classify them according to the category. Second, presentsing the whole data the the translation shift in a coherent and includinge the answer for every formulation of the problem. Third, drawing conclusions based on the result of the study. The research showed that from 47 data, there are 2 types of shift in forms. Namely 35 data shift at the level of syntax, 6 data shift in word category. As for the shift in meaning, there are 2 types, namely 3 data shift of the meaning of the generic to the spesific and 3 data shift according to the cultural point of view.

Copyright (C) 2021, Muhammad Yunus Anis, Hasna Nurul Istiqomah This is an open-access article under the CC-BY-SA license

Keywords:

Arabic-Indonesian translation; translation shift; tazkiyatun nufus wa tarbiyatuha book.

\section{مستخلص البحث}

هذا البحث يحلل تحويل الترجمة في نصوص الأحاديث بترجمتين من كتاب "تزكية النفوس وتربيتها" الذي ألفه ابن رجب، وابن قيم، وإمام الغزالي، وتمت ترجمته المكتوبة الأولى إلى لغة المدف بإعداد إمتحان الشافعي وترجمته الثانية بإعداد عمر مجتهد. وينقسم تحليل البحث إلى قسمين: بيان عن تحويل المبنى و بيان عن تحويل المعنى. وسيبحث تحويل الترجمة في هذه الدراسة في وحدة من الكلمات. الغرض من هذه ونه الدراسة وصف تحويل الترجمة المطبقة في ترجمة الكتاب "تزكية النفوس وتربيتها". أما الطريقة المستخدمة لهذا البحث هي طئيقة طريقة نوعية وصفية. مصدر بياناته هو كتاب "تزكية النفوس وتربيتها" و ترجمتاني من هذا الكتاب. ويجري تحليل البيانات تدريجيا. أولا-، جمع البيانات و تصنيفها وفقا لفئاتا. ثانيا-، تقديم جميع البيانات المحللة بشكل متسق معن ترتيب الإجابات في كل صياغة المشكلة. ثالثا-،

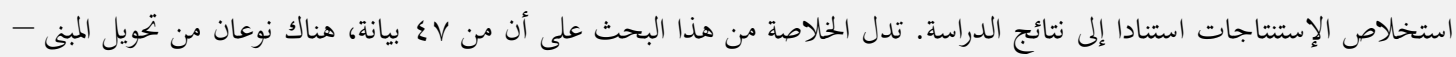

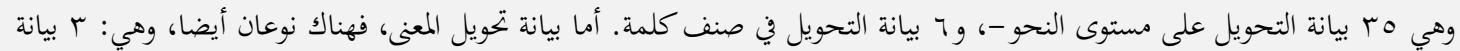
التحويل من المعنى العام إلى المعنى الخاص، وب بيانة التحويل من سبب الإختلاف في وجهة المنظور الثقافي.

كلمات أساسية: الترجمة من اللغة العرب إلى الأندونيسية؛ تحويل الترجمة كتاب تزكية النفوس وتربيتها. 


\section{Pendahuluan}

Perkembangan kegiatan penerjemahan pada zaman sekarang berkembang sangat pesat dan melahirkan banyak kajian terjemahan (Translation Studies) yang juga berkembang dengan cepat. Berbagai teori diajukan oleh para ilmuwan, diantaranya teori yang dikemukakan oleh Simatupang yaitu, menerjemahkan adalah pengalihan makna yang terdapat pada bahasa sumber (BSu) ke dalam bahasa sasaran (BSa) dan mewujudkannya kembali pada bahasa sasaran dengan bentuk-bentuk yang sewajar mungkin menurut aturan-aturan yang berlaku dalam bahasa sasaran. ${ }^{1}$

Simatupang menyatakan bahwa dalam menerjemahkan, selalu ada sesuatu yang hilang dan bergeser, yaitu suatu terjemahan tidak dapat diterjemahkan persis dengan aslinya. ${ }^{2}$ Dengan kata lain, dalam suatu terjemahan selalu terjadi pergeseran. Pergeseran terjadi karena setiap bahasa memiliki aturan-aturan sendiri. Aturan-aturan kebahasaan yang berlaku pada bahasa belum tentu berlaku pada bahasa lain. Hal ini berlaku pada semua unsur bahasa; gramatika, fonologi, dan semantik. ${ }^{3}$ Penelitian terkait pergeseran penerjemahan sangat penting dilakukan, karena hasil dari penelitian tersebut akan dapat dijadikan sebagai landasan untuk menjelaskan karakter gramatika yang ada dalam Bahasa sumber (Arab) ketika dialihbahasakan ke dalam Bahasa sasaran (Indonesia).

Pergeseran dalam terjemahan meliputi pergeseran pada tataran morfem, pergeseran pada tataran sintaksis, pergeseran kategori kata, dan pergeseran pada tataran semantik. Catford juga menyatakan bahwa "shift in translation" atau pergeseran terjemahan artinya berpindah atau bergeser dari korespondensi formal (formal correspondence) dalam proses pemindahan teks dari bahasa sumber (BSu) ke bahasa sasaran (BSa) agar hasil terjemahannya berterima. ${ }^{4}$ Dengan adanya perbedaan aturan dan bentuk pada bahasa, penerjemah perlu mencari padanan yang paling tepat untuk mengungkapkan makna dari bahasa sumber (BSu) ke dalam bahasa sasaran (BSa). Selain itu, struktur gramatikal pada bahasa sumber (BSu) harus disesuaikan pada bahasa sasaran (BSa) agar kalimat yang dihasilkan berterima pada bahasa sasaran. Penelitian pergeseran terjemahan pada kitab Tazkiyatun Nufūs wa Tarbiyatuhā dari bahasa Arab ke bahasa Indonesia terjadi pada tataran sintaksis, pergeseran kategori kata, dan pergeseran pada tataran semantik.

Penelitian ini membahas mengenai pergeseran terjemahan yang terjadi pada teks hadis dalam dua versi terjemahan kitab Tazkiyatun Nufūs wa Tarbiyatuhā karya Ibnu Rajab Al-Hanbali, Ibnu Qayyim, dan Imam Al-Ghazali sebagai teks

1 Maurits D.S. Simatupang, Pengantar Teori Terjemahan (Jakarta: Dirjen Pendidikan Tinggi Dediknas, 2000), 2.

2 Simatupang, 3.

${ }^{3}$ Simatupang, 74.

${ }^{4}$ J. C. Catford, A Linguistic Theory of Translation (London: Oxford University Press, 1965), 73. 
sumber (Tsu) yang diterjemahkan oleh Imtihan Asy-Syafi'i sebagai teks sasaran pertama (TSa) dan diterjemahkan oleh Umar Mujtahid sebagai teks sasaran kedua (TSa). Peneliti melakukan penelitian menggunakan dua versi terjemahan agar pembaca mengetahui bahwa antara satu penerjemah dengan penerjemah yang lain terkedang menerjemahkan dengan cara yang berbeda. Contoh: terjemahan teks pertama banyak melakukan pergeseran, sedangkan terjemahan teks kedua tidak melakukan pergeseran dalam penerjemahan. selain itu, peneliti melakukan kajian menggunakan dua versi terjemahan agar peneliti mampu membandingkan terjadinya pergeseran antara dua teks terjemahan tersebut.

Kitab Tazkiyatun Nufūs wa Tarbiyatuhā adalah satu kitab agama yang di dalamnya membahas mengenai tata cara membersihkan jiwa dari penyakitpenyakit hati yang merujuk pada tiga ulama besar, yaitu Imam Al-Ghazali, Ibu Qayyim Al-Jauziyah, dan Ibnu Rajab Al-Hanbali. Selain menyampaikan materimateri, kitab ini dilengkapi dengan tahqiq hadis, atsar (yang disandarkan kepada shahabat dan tabi'in berupa perkataan atau perbuatan) dan doa-doa sebagai rujukan atau penguat dari isi materi yang disampaikan. Namun, peneliti tidak meneliti keseluruhan data pada kitab tersebut. melainkan hanya meneliti data berupa hadis-hadis yang menjadi rujukan materi yang terdapat pada buku Tazkiyatun Nufūs wa Tarbiyatuhā ditinjau dari sisi penerjemahan untuk membatasi suatu masalah yang ditemukan. Hadis secara istilah yaitu segala sesuatu yang disandarkan kepada Rasulullah shallallahu 'alaihi wa sallam baik berupa perkataan, perbuatan, persetujuan atau sifat. ${ }^{5}$

Alasan peneliti mengkaji kitab Tazkiyatun Nufūs wa Tarbiyatuhā dikarenakan materi yang disampaikan mengenai konsep penyucian jiwa atau membersihkan jiwa. Hal tersebut sangat bagus untuk dipelajari oleh masyrakat dalam rangka menambah wawasan terhadap ilmu agama dan diharapkan masyarakat mampu mengamalkan isi materi yang telah disampaikan pada kitab tersebut. selain itu, masyarakat diharapkan mampu memahami bahwa kaidah yang berlaku pada suatu bahasa belum tentu berlaku pada bahasa lain sehingga, terjadilah adanya pergeseran dalam terjemahan. ${ }^{6}$

Adapun pentingnya penelitian ini, agar dapat diketahui bagaimana variasi pergeseran bentuk dan makna dalam terjemahan hadis-hadis yang terdapat pada kitab Tazkiyatun Nufūs wa Tarbiyatuhā dan mengetahui karakter antara dua bahasa yaitu bahasa Indonesia dan bahasa Arab dan mampu memberikan pengetahuan kepada para pembaca bahwa suatu penerjemahan tidak dapat terlepas dari adanya perbedaan aturan dan bentuk dalam mengungkapkan makna yang menyebabkan adanya pergeseran dalam suatu terjemahan. Selain itu, pentingnya penelitian ini mampu menjadi rujukan bagi para peneliti lain yang

\footnotetext{
${ }^{5}$ Thahan Mahmud, Taisir Musthalah Hadits (Riyadh: Maktabah Al-Ma'arif Lin-Nasyri Wat-Tauzi', 2010), 18.

${ }^{6}$ Simatupang, Pengantar Teori Terjemahan, 74.
} 
akan mengkaji ilmu-ilmu penerjemahan diantaranya yaitu, pergeseran dalam terjemahan.

Berdasarkan uraian latar belakang masalah, peneliti akan membahas mengenai pergeseran terjemahan yaitu pergeseran bentuk dan makna pada terjemahan teks hadis dalam dua versi terjemahan kitab Tazkiyatun Nufüs wa tarbiyatuhā. Adapun tujuan dari penelitian ini yaitu mendeskripsikan pergeseran bentuk dan makna teks hadis dalam dua versi terjemahan kitab Tazkiyatun Nufüs wa Tarbiyatuhā.

Penelitian mengenai pergeseran terjemahan pernah dilakukan, diantaranya; pertama, skripsi karya Akhlada yang berjudul "Pergeseran Bentuk dan Makna Dalam Terjemahan Komil L'Agent 212 (dari bahasa Prancis ke bahasa Indonesia). Dalam penelitian ini ditemukan 56 data terkait pergeseran bentuk dan 53 data terkait pergeseran makna. ${ }^{7}$ Kedua, skripsi karya Nisak yang berjudul "Pergeseran Penerjemahan Dalam Novel Na'ib Izrail Karya Yusuf As-Siba'i. Hasil dari penelitian ini ditemukan sebanyak 115 data yang mengalami pergeseran bentuk dan 37 data yang mengalami pergeseran makna. ${ }^{8}$

Penelitian mengenai perbandingan pernah dilakukan yaitu, karya Sari Nurul Intan yang berjudul "Analisis Perbandingan Pergeseran Teknik Penerjemahan Istilah Tabu Dalam Film The Wolf of Wall Street Dan Dua Terjemahannya (Subtitle Resmi VCD Dan Amatir Dari Situs Subscene.com) Serta Dampaknya Pada Kualitas Terjemahan". Hasil dari penelitian ini ditemukan dua bentuk istilah tabu; kata dan frasa. Pada subtitle VCD ditemukan 6 teknik penerjemahan dan pada subtitle amatir ditemukan 7 teknik penerjemahan. ${ }^{9}$

Penelitian mengenai kitab tazkiyatun nafs pernah dilakukan oleh Sayfudin dengan judul skripsi "Konsep Tazkiyatu Nafs perspektif Al-Ghazali dalam Pendidikan Akhlak". ${ }^{10}$ Penelitian ini membahas bagaimana konsep Tazkiyatun Nafs dalam pendidikan akhlak menurut Al-Ghazali. Secara keseluruhan, kajian pustaka yang dicantumkan memberikan gambaran kepada penulis untuk mencari data dan menganalisis data dalam penelitian ini.

Berdasarkan kajian pustaka tersebut, dapat disimpulkan bahwa penelitian mengenai pergeseran terjemahan pada teks hadis dalam terjemahan kitab Tazkiyatun Nufūs wa Tarbiyatuhā yang diterjemahkan oleh Imtihan Asy-Syafi'i

7 Nada Akhlada, “Pergeseran Bentuk Dan Makna Dalam Terjemahan Komik L Agent 212 (Dari Bahasa Prancis Ke Bahasa Indonesia)" (Skripsi, Universitas Negeri Yogyakarta, 2015), https://eprints.uny.ac.id/13624/.

8 Choirun Nisak, "Pergeseran Penerjemahan Dalam Novel Na'ib Izrail Karya Yusuf As-Siba'i" (Surakarta, Universitas Sebelas Maret, 2019).

9 Nurul Intan Sari, Nababan M.r, dan Djatmika Djatmika, "Analisis Perbandingan Teknik Penerjemahan Istilah Tabu Dalam Film The Wolf Of Wall Street Dan Dua Terjemahannya (Subtitle Resmi VCD Dan Amatir Dari Situs Subscene.Com) Serta Dampaknya Pada Kualitas Terjemahan," PRASASTI: Journal of Linguistics 1, no. 1 (2016): 80-102, https://doi.org/10.20961/prasasti.v1i1.910.

${ }^{10}$ Nur Sayfudin, "Konsep Tazkiyatun Nafs Perspektif Al-Ghozali Dalam Pendidikan Akhlak" (Skripsi, IAIN Metro, 2018), https://repository.metrouniv.ac.id/id/eprint/1673/. 
sebagai teks sasaran pertama dan terjemahan Umar Mujtahid sebagai teks sasaran kedua belum pernah dilakukan. Selain itu, penelitian sebelumnya mengenai pergeseran terjemahan menggunakan satu objek bahasa sasaran, maka peneliti melakukan penelitian dengan menambahkan hal yang baru yaitu, menggunakan dua objek buku terjemahan sebagai bahasa sasaran.

Penelitian ini diharapkan mampu mengembangkan ilmu pengetahuan mengenai penerjemahan terutama penerjemahan Arab-Indonesia, agar pembaca mampu memahami mengenai penelitian pergeseran terjemahan terhadap dua objek kitab terjemahan dan mampu memahami variasi yang berbeda dari penelitian yang pernah dilakukan dan mampu menjadi rujukan untuk menerapkan dan mengimplementasikan teori ilmu-ilmu penerjemahan yang lain.

\section{Metode Penelitian}

Metode yang digunakan dalam penelitian ini yaitu metode deskriptif kualitatif, yaitu sebuah metode yang digunakan oleh peneliti untuk menemukan pengetahuan atau teori terhadap penelitian pada satu waktu tertentu. Metode ini digunakan dalam penelitian bahasa, khususnya terkait dengan produk penerjemahan, untuk mengumpulkan data-data dan menggambarkannya secara alamiah. ${ }^{11}$

Penelitian ini menggunakan dua sumber data yaitu sumber data primer dan sumber data sekunder. Sumber data primer adalah sumber data yang langsung memberikan data kepada pengumpul data. Data dikumpulkan sendiri oleh peneliti langsung dari sumber pertama atau tempat penelitian, sedangkan sumber data sekunder adalah sumber data yang memberikan data kepada pengumpul data secara tidak langsung. Dalam penelitian ini yang menjadi sumber data sekunder adalah literatur yang berkaitan dengan penelitian yang dilakukan. ${ }^{12}$ Penelitian ini difokuskan pada tataran kata mengenai kajian pergeseran bentuk dan makna terhadap hadis-hadis yang terdapat pada kitab Tazkiyatun Nufūs wa Tarbiyatuhā yang diterjemahkan oleh Imtihan Asy-Syafi'i sebagai teks sasaran pertama dan terjemahan oleh Umar Mujtahid sebagai teks sasaran kedua.

Teknik penelitian yang digunakan terdiri dari 3 alur kegiatan yaitu, pertama, reduksi data diartikan sebagai proses pemilihan, pemusatan perhatian pada penyederhanaa, pengabstrakan, dan transformasi data-data kasar yang muncul dari catatan-catatan yang tertulis di lapangan, yaitu melakukan pertimbangan bahwa data mengenai pergeseran terjemahan dalam kitab Tazkiyatun Nufūs wa Tarbiyatuhā berjumlah cukup banyak, sehingga diperlukan pemilihan data sesuai dengan kebutuhan dalam pemecahan masalah. Kedua, sajian data diartikan sebagai sekumpulan informasi yang tersusun dan dapat memberi kemungkinan dengan adanya penarikan kesimpulan dan pengambilan tindakan. Ketiga, penarikan

\footnotetext{
${ }^{11}$ Mukhtar, Metode Praktis Penelitian Deskriptif Kualitatif (Jakarta: GP Press Group, 2013), 10.

${ }^{12}$ Sugiyono, Metode Penelitian Kombinasi (Mix Methods) (Bandung: Alfabeta, 2015), 137.
} 
kesimpulan atau verivikasi merupakan bagian dari satu kegiatan konfigurasi yang utuh. Kesimpulan-kesimpulan yang ada juga diverivikasi selama penelitian berlangsung. Verivikasi dilakukan dengan cara menguji kebenaran, kekokohan, dan kecocokan data dari makna-makna yang muncul, yakni yang merupakan

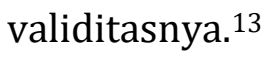

\section{Hasil dan Pembahasan}

\section{Analisis Data Pergeseran Bentuk}

Pergeseran penerjemahan dalam penelitian ini berdasarkan teori pergeseran penerjemahan yang dikemukakan oleh Simatupang yaitu, dengan adanya perbedaan kaidah dan bentuk untuk mengungkapkan makna di antara berbagai bahasa, maka ditemukan adanya pergeseran yang terjadi dalam penerjemahan. ${ }^{14}$ Pergeseran bentuk pada penelitian ini yaitu, pergeseran bentuk pada tataran sintaksis dari kata ke frasa dan pergeseran kategori kata yaitu, dari nomina ke verba. penelitian ini difokuskan pada tataran "kata" sebagai tolak ukur analisis dalam penelitian kitab Tazkiyatun Nufūs wa Tarbiyatuhā. Dalam bahasa Arab, kata disebut Al-kalimatu. Kata dalam bahasa Arab terbagi menjadi 3, yaitu ism (nomina), fi'l (kata kerja), dan charf (partikel). ${ }^{15}$

Pada penelitian ini, pergeseran pada tataran sintaksis dari kata ke frasa hanya terdiri dari satu kelompok saja, yaitu nomina (kata benda). Nomina (kata benda) atau ism memiliki tanda-tanda sebagai berikut: (a) menerima tanwin, (b) menerima alif lam, (c) didahului salah satu huruf nida (panggilan), dan (d) diawali salah satu dari charf jar (kata depan). Selain itu, ism dalam bahasa Arab dapat ditinjau dari berbagai kaidah sharaf (perubahan kata) di antaranya: (a) ditinjau dari jenisnya, (b) ditinjau dari jumlahnya dan lain-lain. Unsur-unsur di atas dapat memberikan dampak dalam penerjemahan khususnya pergeseran, karena bahasa Indonesia tidak memiliki bentuk bilangan dan gender (laki-laki atau perempuan) dalam nominanya berbeda dengan bahasa Arab. Misal, dalam bahasa Arab ism (nomina) yang menandakan muannats (perempuan) pada umumya ditandai

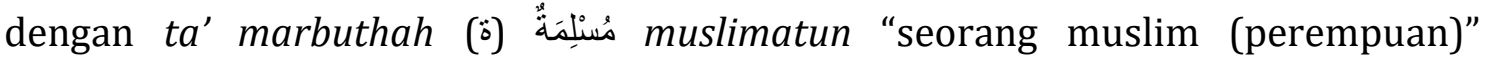
sedangkan ism yang menandakan mudzakkar (laki-laki) tidak ditandai dengan $t a^{\prime}$

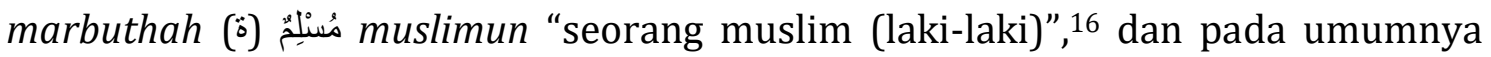
dalam bahasa Indonesia keduanya diterjemahkan menjadi "seorang muslim" yang berbeda dengan keterangan di atas.

13 Matthew B. Miles dan A. Michael Huberman, Analisis Data Kualitatif, trans. oleh Tjetjep Rohendi (Jakarta: Penerbit Universitas Indonesia, 1992), 16.

${ }^{14}$ Simatupang, Pengantar Teori Terjemahan, 74.

15 Fuad Ni'mah, Mulakhkhash Qawaidu Al-Lughati Al-Arabiyyah (Beirut: Daru Ats-Tsaqafah AlIslamiyyah, 1988), 17.

${ }^{16}$ Aunur Rofiq, Ringkasan Kaedah Bahasa Arab (Gresik: Yayasan Al-Furqon Al-Islami, 2018$), 7$. 


\section{Pergeseran Pada Tataran Sintaksis dari Kata ke Frasa}

Kata (nomina) adalah seluruh kata yang mengacu pada manusia, binatang, benda, dan konsep atau pengertian. ${ }^{17}$ Sedangkan frasa menurut Kridalaksana adalah gabungan kata yang terdiri dari dua kata atau lebih yang bersifat tidak predikatif. ${ }^{18}$ Dalam bahasa Arab, ism (nomina) dapat ditinjau dari kejelasannya, yaitu ism nakirah dan ism ma'rifah. Ism nakirah adalah ism yang belum jelas bendanya (masih umum) dan memiliki ciri atau tanda berupa tanwin, sedangkan ism ma'rifah adalah ism yang sudah jelas bendanya (telah ditentukan) dan salah satu ciri atau tandanya berupa alif lam (ال).19 Tanwin pada penerjemahan dapat memberikan efek dalam pergeseran. Misal, kata تَنْمِنِ tilmīdzun diterjemahkan menjadi "seorang murid" dan disebut sebagai ism nakirah.

Penelitian ini akan memaparkan pergeseran bentuk pada tataran sintaksis dari kata ke frasa pada teks hadis dalam kitab Tazkiyatun Nufūs wa Tarbiyatuhā dengan contoh sebagai berikut:

Tabel 1: Perbandingan pergeseran dari kata (nomina dengan penanda tanwin) ke rasa

\begin{tabular}{|c|c|c|}
\hline Tsu & TSa (1) & TSa (2) \\
\hline 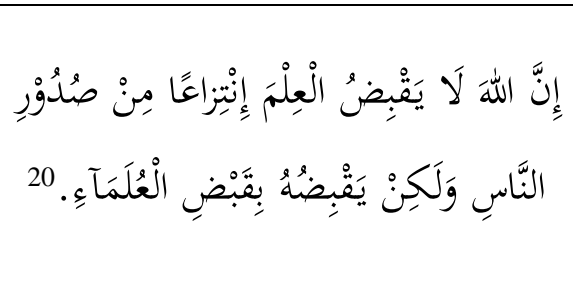 & $\begin{array}{c}\text { Sesungguhnya Allah tidak } \\
\text { mencabut ilmu langsung } \\
\text { dari dada umat manusia. } \\
\text { Tetapi, Ia mencabutnya } \\
\text { dengan mewafatkan para } \\
\text { ulama. }{ }^{21}\end{array}$ & $\begin{array}{c}\text { Sungguh, Allah tidak } \\
\text { mencabut ilmu begitu saja } \\
\text { dari dada umat manusia. } \\
\text { Namun, Ia mencabut ilmu } \\
\text { dengan mewafatkan } \\
\text { ulama. }{ }^{22}\end{array}$ \\
\hline
\end{tabular}

Pada tabel (1), data yang dicantumkan mengalami pergeseran bentuk pada tataran sintaksis dari kata ke frasa yaitu kata اُعَُْ al-ulamā'u (TSu) pada TSa (1) diterjemahkan menjadi "para ulama". Sedangkan pada TSa (2) diterjemahkan

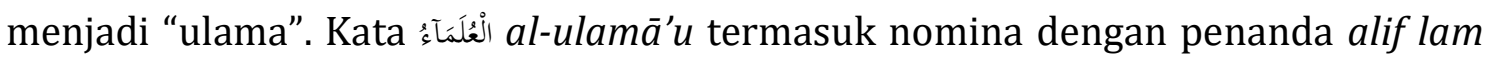
dalam bentuk jamak (kemajemukan). Jamak adalah sesuatu yang menunjukkan kepada lebih dari dua laki-laki ataupun perempuan. ${ }^{23}$ Jamak (kemajemukan) dalam bahasa Arab dibagi menjadi 3, yaitu jamak mudzakkar salim (hitungan lebih dari dua yang menunjukkan laki-laki), jamak muannats salim (hitungan lebih dari dua yang menunjukkan perempuan), dan jamak taksir (berjumlah tiga atau lebih yang berubah dari bentuk tunggalnya). ${ }^{24}$

\footnotetext{
${ }^{17}$ Hasan Alwi dkk., Tata Bahasa Baku Bahasa Indonesia Edisi Ketiga (Jakarta: Balai Pustaka, 1998), 213.

${ }^{18}$ Harimurti Kridalaksana, Kamus Linguistik (Jakarta: Gramedia Pustaka Utama, 2008), 9.

${ }^{19}$ Rofiq, Ringkasan Kaedah Bahasa Arab, 14.

20 Imtihan Asy-Syafi'i, Tazkiyatun Nafs Konsep Penyucian Jiwa Menurut Ulama Salafushshalih (Solo: Pustaka Arafah, 2004), 22.

${ }^{21}$ Asy-Syafi'i, 23.

22 Asy-Syafi'i, 26.

${ }^{23} \mathrm{Ni}$ mah, Mulakhkhash Qawaidu Al-Lughati Al-Arabiyyah, 21.

${ }^{24} \mathrm{Ni}$ mah, 13.
} 


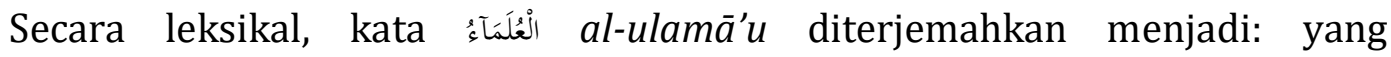
terpelajar, ${ }^{25}$ sarjana, yang mengetahui, ${ }^{26}$ berilmu, ${ }^{27}$ sedangkan menurut KBBI, kata "ulama" diartikan sebagai "orang yang ahli dalam hal agama islam". ${ }^{28}$

Setelah menganalisis data yang ditemukan ditinjau dari sisi gramatikal (tata bahasa) dan dalalah (makna), selanjutnya peneliti membahas konteks data untuk menjelaskan adanya pergeseran yang terjadi pada data tersebut dari sisi luar

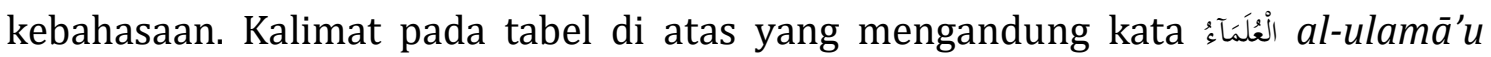
membahas ilmu pertama yang akan dicabut adalah ilmu yang bermanfaat, setelah itu yang bertahan adalah ilmu lisan. Kemudian manusia meremehkan dan tidak mengamalkan petunjuk ilmu lisan, baik yang menyampaikan ilmu ataupun yang lain. Selanjutnya, ilmu tersebut lenyap seiring lenyapnya orang-orang yang menyampaikannya. ${ }^{29}$ Yang dimaksud "orang-orang yang menyampaikan" pada hadis tersebut adalah الْعَلَكَاءُ al-ulamā'u (orang yang ahli dalam agama islam).

Dengan demikian, pada TSa (1) mengalami pergeseran bentuk menjadi frasa, sedangkan pada TSa (2) tidak mengalami pergeseran bentuk dan peneliti lebih condong pada hasil terjemahan TSa (1) yaitu "para ulama" dan pada bahasa sasaran yaitu bahasa Indonesia, kata jamak (kemajemukan) biasanya dengan mengulang nomina yang bersangkutan atau menggunakan kata lain yang menyatakan konsep lebih dari satu atau banyak, seperti dua, beberapa, banyak, para, tanpa mengubah atau mengulang bentuk nomina yang bersangkutan. ${ }^{30}$

\section{Pergeseran Kategori Kata}

Selain pergeseran pada tataran sintaksis, penelitian ini juga membahas pergeseran pada kategori kata. Menurut Verhaar kategori sintaksis adalah "kelas kata" seperti, nomina, verba, ajektiva, adverbia, adposisi (preposisi atau posposisi), dan lain sebagainya. ${ }^{31}$ Dalam bahasa Arab, kata adalah lafadz yang menunjukkan suatu makna yang mufrad (tunggal). ${ }^{32}$ Kata dalam bahasa Arab, dibagi menjadi 3: 1) ism (nomina atau kata benda), 2) fi'l (verba atau kata kerja), dan 3) charf (partikel). ${ }^{33}$

${ }^{25}$ Ahmad Warson Munawwir, Al-Munawwir Kamus Arab-Indonesia (Surabaya: Pustaka Progressif, 1997), 966.

${ }^{26}$ Adib Bisri dan Munawwir A. Fatah, Kamus Al-Bisri (Surabaya: Pustaka Progressif, 1999), 517.

${ }^{27}$ Mahmud Yunus, Kamus Arab-Indonesia (Jakarta: PT. Hidakarya Agung, 1990), 278.

28 Departemen Pendidikan Nasional, Kamus Bahasa Indonesia (Jakarta: Pusat Bahasa, 2008), 1582.

${ }^{29}$ Ahmad Farid, Tazkiyatun Nafs (Solo: Taqiya Publishing, 2015), 28.

${ }^{30}$ Simatupang, Pengantar Teori Terjemahan, 74.

${ }^{31}$ J.M.W Verhaar, Asas-Asas Linguistik Umum (Yogyakarta: Gadjah Mada University Press, 2016), 170.

32 Musthafa Al-Ghulayaini, Jami'u Ad-Durus Al-Arabiyyah (Beirut: Dar Al-kotob Al-IImiyah, 2017),

8.

\footnotetext{
${ }^{33}$ Ni'mah, Mulakhkhash Qawaidu Al-Lughati Al-Arabiyyah, 17.
} 
Pada penelitian teks hadis dalam kitab Tazkiyatun Nufūs wa Tarbiyatuhā, akan dibahas tentang pergeseran pada kategori kata, yaitu pergeseran dari nomina ke verba dengan contoh sebagai berikut:

Tabel 2: Perbandingan Pergeseran dari Nomina dalam TSu ke verba dalam TSa (1) dan TSa (2)

\begin{tabular}{|c|c|c|}
\hline TSu & TSa (1) & TSa (2) \\
\hline 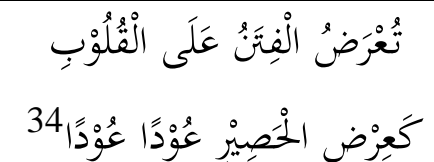 & $\begin{array}{l}\text { Musibah (fitnah) itu masuk ke } \\
\text { dalam hati seperti dianyamnya } \\
\text { tikar, sehelai demi sehelai. }{ }^{35}\end{array}$ & $\begin{array}{l}\text { Fitnah-fitnah dilekatkan di hati } \\
\text { laksana tikar yang dianyam satu } \\
\text { lembar demi satu lembar. }{ }^{36}\end{array}$ \\
\hline
\end{tabular}

Pada tabel (2) terdapat pergeseran kategori kata dari nomina ke verba, yaitu kata كَعْرضِ ka'irdhi (TSu), pada TSa (1) dan TSa (2) diterjemahkan menjadi "dianyam". Kata كَعِرْض ka'irdhi pada TSu termasuk nomina yang ditandai dengan charf jar. ${ }^{37}$ Charf jar adalah huruf yang menghubungkan sesuatu yang terjadi sebelumnya kepada ism setelahnya. ${ }^{38}$ Charf jar terdiri dari 18 huruf. ${ }^{39}$ Salah satu di

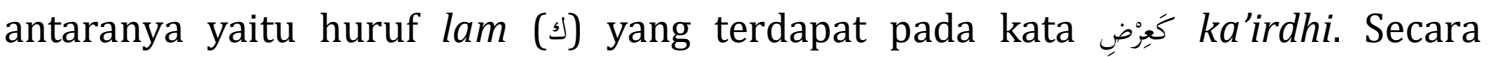
leksikal, kata عرْض 'irdhu diterjemahkan menjadi "membentangkan".40 Adapun dalam TSa, kata عرِضْ 'irdhu diterjemahkan menjadi verba "dianyam". verba atau kata kerja dalam bahasa Arab adalah kata yang menunjukkan atas terjadinya sesuatu pada waktu tertentu. ${ }^{41}$

Setelah menganalisis data yang ditemukan ditinjau dari sisi gramatikal (tata bahasa) dan dalalah (makna), selanjutnya peneliti membahas konteks data untuk menjelaskan adanya pergeseran yang terjadi pada data tersebut dari luar sisi kebahasaan. Kalimat pada tabel di atas yang mengandung kata كَ ka'irdhi membahas mengenai penyebab sakitnya hati yaitu musibah (fitnah yang masuk dalam hati seperti tikar yang dianyam sehelai demi sehelai. ${ }^{42}$

Dalam proses analisis di atas, ditemukan bahwa bahasa memiliki dua sisi atau tingkat (level) yaitu tingkat pengungkapan (level expression) dan tingkat isi (level content). Berbagai bahasa memiliki satuan yang berbeda tingkat pengungkapannya, tetapi sama pada tingkat isinya. Contoh kata pada Bsu

\footnotetext{
${ }^{34}$ Ibnu Rajab Al-Hambali, Ibnu Qayyim Al-Jauziyah, dan Abi Hamid Al-Ghazali, Tazkiyatun Nufus wa Tarbiyatuha Kama Yuqarriruhu Ulama As-Salaf (Beirut: Dar Al Qolam, 1985), 30.

${ }^{35}$ Asy-Syafi'i, Tazkiyatun Nafs Konsep Penyucian Jiwa Menurut Ulama Salafushshalih, 32.

${ }^{36}$ Farid, Tazkiyatun Nafs, 37.

${ }^{37}$ Al-Ghulayaini, Jami'u Ad-Durus Al-Arabiyyah, 9.

${ }^{38}$ Al-Ghulayaini, 125.

${ }^{39} \mathrm{Ni}$ mah, Mulakhkhash Qawaidu Al-Lughati Al-Arabiyyah, 148.

40 Munawwir, Al-Munawwir Kamus Arab-Indonesia, 916.

${ }^{41} \mathrm{Ni}$ mah, Mulakhkhash Qawaidu Al-Lughati Al-Arabiyyah, 18.

${ }^{42}$ Asy-Syafi'i, Tazkiyatun Nafs Konsep Penyucian Jiwa Menurut Ulama Salafushshalih, 32.
} 
ka'irdhi diterjemahkan pada TSa (1) "dianyam" dan pada TSa (2) diterjemahkan "dianyam". Hal tersebut berbeda pada tingkat pengungkapan, yaitu pada TSu pengungkapan berupa ism dan pada TSa berupa fi'l, namun isinya sama, yaitu isi keduanya sama-sama dianyam. ${ }^{43}$ Dengan demikian, pada TSa (1) dan TSa (2) keduanya mengalami pergeseran bentuk dari nomina ke verba dan peneliti sepakat pada hasil terjemahan TSa (1) dan TSa (2).

\section{Analisis Data Pergeseran Makna}

Selain kemungkinan terjadinya pergeseran di bidang struktur dan kategori kata, pergeseran pun bisa terjadi di bidang semantik. Menurut Simatupang, pergeseran makna dapat terjadi karena adanya perbedaan sudut pandang dan budaya penutur yang beragam atau berbeda-beda. Pergeseran di bidang makna dapat mengakibatkan bahwa terkadang memindahkan makna yang terdapat pada teks sumber ke teks sasaran tidaklah selalu utuh dan tepat. ${ }^{44}$ Pergeseran makna terdiri dari, (a) pergeseran dari makna generik ke makna spesifik dan sebaliknya, (b) pergeseran makna karena adanya sudut pandang dan budaya.

\section{Pergeseran dari Makna Generik ke Makna Spesifik}

Pada penelitian teks hadis dalam kitab Tazkiyatun Nufūs wa Tarbiyatuhā, ditemukan data mengenai pergeseran dari makna generik ke makna spesifik dengan contoh data sebagai berikut:

Tabel 3: Perbandingan Pergeseran dari Makna Generik dalam TSu ke Makna Spesifik

\begin{tabular}{|c|c|c|}
\hline TSu & TSa (1) & Tsa (2) \\
\hline 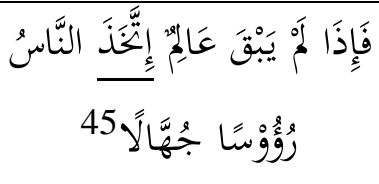 & $\begin{array}{c}\text { Maka jika tidak ada lagi seorang } \\
\text { alim pun, manusia akan } \\
\text { mengangkat orang-orang yang } \\
\text { bodoh sebagai pemimpin. }{ }^{46}\end{array}$ & $\begin{array}{c}\text { Ketika tidak tidak lagi tersisa } \\
\text { seorang ulama pun, orang-orang } \\
\text { mengangkat pemimpin- } \\
\text { pemimpin yang bodoh. }{ }^{47}\end{array}$ \\
\hline
\end{tabular}

Pada tabel (3) terdapat pergeseran makna dari makna generik ke makna spesifik, yaitu kata إِ menjadi "mengangkat". Secara leksikal pada kamus Munawwir ${ }^{48}$ dan Kamus Tiga

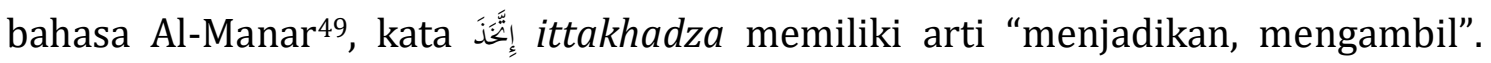

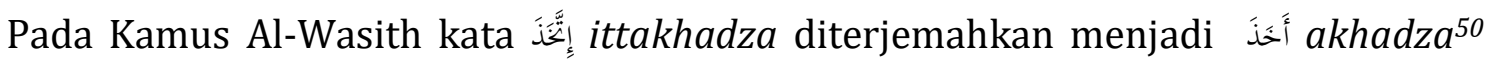
"mengambil". ${ }^{51}$ Menurut KBBI kata "mengambil” memiliki arti "memegang sesuatu

${ }^{43}$ Salihen Moentaha, Bahasa dan Terjemahan: Language and Translation (Bekasi: Kesaint Blanc, 2006), 10.

${ }^{44}$ Simatupang, Pengantar Teori Terjemahan, 78.

45 Al-Hambali, Al-Jauziyah, dan Al-Ghazali, Tazkiyatun Nufus wa Tarbiyatuha Kama Yuqarriruhu Ulama As-Salaf, 22.

${ }^{46}$ Asy-Syafi'i, Tazkiyatun Nafs Konsep Penyucian Jiwa Menurut Ulama Salafushshalih, 23.

47 Farid, Tazkiyatun Nafs, 26.

${ }^{48}$ Munawwir, Al-Munawwir Kamus Arab-Indonesia, 11.

49 Idrus Al-Kaf, Kamus Tiga Bahasa Al-Manar (Surabaya: Karya Utama, 1996), 20.

${ }^{50}$ Syauqi Dhaif, Al-Mu'jam Al-Wasith (Mesir: Maktabah Asy-Syuruq Ad-Dauliyyah, 2004), 8.

${ }^{51}$ Munawwir, Al-Munawwir Kamus Arab-Indonesia, 11. 
lalu dibawa, diangkat, dipergunakan, disimpan".52 Dengan demikian, kata ittakhadza (TSu) termasuk kategori kata yang bermakna generik karena sifarnya masih umum dan memiliki banyak makna, jadi dalam terjemahannya disesuaikan dengan konteks.

Setelah menganalisis data yang ditemukan ditinjau dari sisi gramatikal (tata bahasa) dan dalalah (makna), selanjutnya peneliti membahas konteks data untuk menjelaskan adanya pergeseran yang terjadi pada data tersebut dari luar sisi kebahasaan. Kalimat pada tabel di atas yang mengandung kata إِ membahas tentang bagaimana Allah mencabut ilmu dari manusia yaitu, Allah mencabut ilmu dari manusia dengan cara mewafatkan orang-orang berilmu sehingga tersisalah orang-orang bodoh yang akan diangkat menjadi pemimpin. ${ }^{53}$

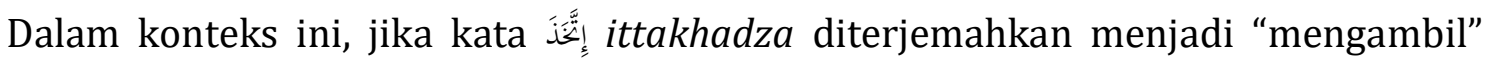
maka kurang tepat, maka diterjemahkan dengan kata "mengangkat" sehingga sesuai dengan kontesk terjemahan tersebut. Dengan demikian, terjemahan pada dua teks tersebut mengalami pergeseran dari makna generik ke makna spesifik yaitu kata إِ sepakat pada hasil kedua terjemahan tersebut.

\section{Pergeseran Menurut Sudut Pandang Budaya}

Penelitian pada teks hadis dalam kitab Tazkiyatun Nufūs wa Tarbiyatuhā, ditemukan data mengenai pergeseran makna menurut sudut pandang budaya dengan contoh sebagai berikut:

Tabel 4: Perbandingan Pergeseran Menurut Sudut Pandang Budaya Pada TSa (1) dan TSa (2)

\begin{tabular}{|c|c|c|}
\hline TSu & TSa (1) & TSa (2) \\
\hline 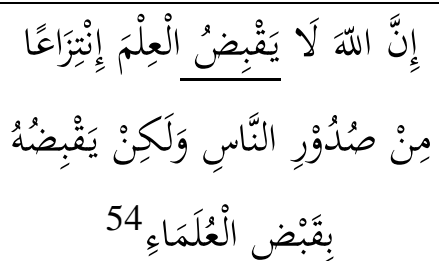 & $\begin{array}{l}\text { Sesungguhnya Allah tidaklah } \\
\text { mencabut ilmu langsung } \\
\text { dari dada manusia, tetapi } \\
\text { Dia mencabutnya dengan } \\
\text { mewafatkan para ulama. }{ }^{55}\end{array}$ & $\begin{array}{c}\text { Sungguh, Allah tidak mencabut } \\
\text { ilmu begitu saja dari dada } \\
\text { umat manusia. Namun, Ia } \\
\text { mencabut ilmu dengan } \\
\text { mewafatkan ulama. }{ }^{56}\end{array}$ \\
\hline
\end{tabular}

Pada tabel (4) terdapat pergeseran makna menurut sudut pandang budaya (berupa fi'l mudhari) yaitu kata يَنْبِ yaqbidhu (TSu), pada TSa (1) dan TSa (2) diterjemahkan menjadi "mencabut". Kata يَنْفِضُ yaqbidhu termasuk kategori fi'l

\footnotetext{
52 Departemen Pendidikan Nasional, Kamus Bahasa Indonesia, 50.

53 Asy-Syafi'i, Tazkiyatun Nafs Konsep Penyucian Jiwa Menurut Ulama Salafushshalih, 23.

${ }^{54}$ Al-Hambali, Al-Jauziyah, dan Al-Ghazali, Tazkiyatun Nufus wa Tarbiyatuha Kama Yuqarriruhu Ulama As-Salaf, 22.

${ }^{55}$ Asy-Syafi'i, Tazkiyatun Nafs Konsep Penyucian Jiwa Menurut Ulama Salafushshalih, 23.

${ }^{56}$ Farid, Tazkiyatun Nafs, 26.
} 
mudhari, fi'l mudhari adalah fi'l yang menunjukkan terjadinya sesuatu pada waktu pembicaraan atau setelah pembicaraan (sekarang atau masa depan). ${ }^{57}$

Kata يَ يَتْبض yaqbidhu, pada kamus Munawwir58 dan Kamus Tiga Bahasa AlManar ${ }^{59}$ diterjemahkan menjadi "menggenggam, memegang". Dalam kamus Al-

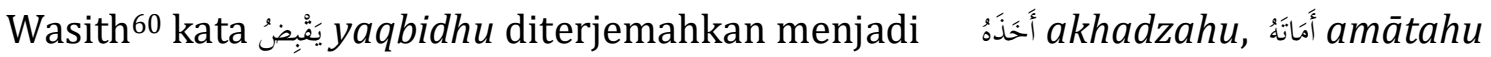
"mengambil" 61 dan "mati". 62 Jika kata يَعْبِضِ yaqbidhu digabungkan dengan "ilmu dari dada manusia", maka kurang tepat jika diterjemahkan menjadi "mengambil atau mati". Perubahan ini terjadi akibat adanya perbedaan sudut pandang budaya antara bahasa Arab sebagai bahasa sumber dengan bahasa Indonesia sebagai bahasa sasaran.

Setelah menganalisis data yang ditemukan ditinjau dari sisi gramatikal (tata bahasa) dan dalalah (makna), selanjutnya peneliti membahas konteks data untuk menjelaskan adanya pergeseran yang terjadi pada data tersebut dari sisi luar kebahasaan. Kalimat pada tabel di atas yang mengandung kata يَ يَتِضِ yaqbidhu membahas tentang bahwa Allah tidak mencabut ilmu langsung dari dada manusia, namun dengan cara mewafatkan orang-orang berilmu.63 Dengan demikian, terjemahan tersebut mengalami pergeseran makna sudut pandang budaya, yaitu kata يَعْبِ yaqbidhu (TSu), pada TSa (1) dan TSa (2) diterjemahkan menjadi "mencabut" dan peneliti sepakat pada hasil terjemahan kedua teks tersebut.

Pergeseran tersebut terjadi karena kebudayaan antara bangsa Arab dan bangsa Indonesia berbeda. Hal tersebut dibuktikan melalui Kamus Bahasa Indonesia (2008) sebagai bahasa sasaran, yaitu bahasa Indonesia, dan kamus Munawwir, kamus Al-Wasith dan kitab Tazkiyatun Nufūs wa Tarbiyatuhā sebagai bahasa sumber, yaitu bahasa Arab.

\section{Kesimpulan}

Berdasarkan hasil analisis pada pembahasan terhadap teks hadis dalam dua versi terjemahan kitab TNT yang diterjemahkan oleh Imtihan Asy-Syafi'i sebagai Tsa pertama dan terjemahan Umar Mujtahid sebagai Tsa kedua ditemukan sebanyak 35 data mengenai pergeseran bentuk pada tataran sintaksis dari kata ke frasa dan ditemukan sebanyak 6 data pergeseran bentuk kategori kata. Pada hasil penelitian tersebut dapat ditarik kesimpulan bahwa pergeseran bentuk terjadi disebabkan oleh adanya perbedaan struktur antara BSu dan BSa. Adapun pergeseran makna ditemukan sebanyak 6 data dan dapat diketahui bahwa

\footnotetext{
${ }^{57}$ Ni'mah, Mulakhkhash Qawaidu Al-Lughati Al-Arabiyyah, 22.

${ }^{58}$ Munawwir, Al-Munawwir Kamus Arab-Indonesia, 1086.

${ }^{59}$ Al-Kaf, Kamus Tiga Bahasa Al-Manar, 508.

${ }^{60}$ Dhaif, Al-Mu'jam Al-Wasith, 711.

${ }^{61}$ Munawwir, Al-Munawwir Kamus Arab-Indonesia, 11.

62 Al-Kaf, Kamus Tiga Bahasa Al-Manar, 526.

${ }^{63}$ Asy-Syafi'i, Tazkiyatun Nafs Konsep Penyucian Jiwa Menurut Ulama Salafushshalih, 23.
} 
pergeseran pada bidang makna dapat terjadi karena dalam memindahkan suatu makna dari Bsu ke dalam BSa terkadang tidak tepat dan utuh. Hasil dari 47 data yang ditemukan, bahwa antara teks (1) dan teks (2) pada terjemahan tersebut, pergeseran yang banyak terjadi yaitu pada terjemahan teks (1) dengan jumlah 32 data. Sedangkan, pergeseran yang terjadi yaitu pada terjemahan teks (2) berjumlah 28 data. Secara keseluruhan dari terjemahan teks (1) dan teks (2), penulis lebih condong pada terjemahan teks (1) dibandingkan dengan terjemahan teks (2) sesuai dengan data yang didapatkan pada penelitian ini. Kebaruan (novelty) dari penelitian ini adalah analisis pergeseran penerjemahan, baik dari sisi bentuk dan sisi makna, yang belum pernah dikaji oleh para peneliti sebelumnya, hal ini menjadi celah penelitian, sehingga kedepannya, penelitian terkait hadis akan dapat dielaborasi secara maksimal dan komprehensif dari sisi penerjemahan. Perlu diketahui bahwa penelitian ini hanya membahas pergeseran bentuk dan makna hanya pada tataran kata. Oleh karena itu, bagi peneliti selanjutnya disarankan untuk melakukan penelitian lebih mendalam dengan menambahkan kajian frasa, klausa, kalimat atau wacana.

\section{Daftar Pustaka}

Akhlada, Nada. "Pergeseran Bentuk Dan Makna Dalam Terjemahan Komik L Agent 212 (Dari Bahasa Prancis Ke Bahasa Indonesia).” Skripsi, Universitas Negeri Yogyakarta, 2015. https://eprints.uny.ac.id/13624/.

Al-Ghulayaini, Musthafa. Jami'u Ad-Durus Al-Arabiyyah. Beirut: Dar Al-kotob AlIlmiyah, 2017.

Al-Hambali, Ibnu Rajab, Ibnu Qayyim Al-Jauziyah, dan Abi Hamid Al-Ghazali. Tazkiyatun Nufus wa Tarbiyatuha Kama Yuqarriruhu Ulama As-Salaf. Beirut: Dar Al Qolam, 1985.

Al-Kaf, Idrus. Kamus Tiga Bahasa Al-Manar. Surabaya: Karya Utama, 1996.

Alwi, Hasan, Soenjono Dardjowidjojo, Hans Lapoliwa, dan Anton M. Moeliono. Tata Bahasa Baku Bahasa Indonesia Edisi Ketiga. Jakarta: Balai Pustaka, 1998.

Asy-Syafi'i, Imtihan. Tazkiyatun Nafs Konsep Penyucian Jiwa Menurut Ulama Salafushshalih. Solo: Pustaka Arafah, 2004.

Bisri, Adib, dan Munawwir A. Fatah. Kamus Al-Bisri. Surabaya: Pustaka Progressif, 1999.

Catford, J. C. A Linguistic Theory of Translation. London: Oxford University Press, 1965.

Departemen Pendidikan Nasional. Kamus Bahasa Indonesia. Jakarta: Pusat Bahasa, 2008.

Dhaif, Syauqi. Al-Mu'jam Al-Wasith. Mesir: Maktabah Asy-Syuruq Ad-Dauliyyah, 2004.

Farid, Ahmad. Tazkiyatun Nafs. Solo: Taqiya Publishing, 2015. 
Kridalaksana, Harimurti. Kamus Linguistik. Jakarta: Gramedia Pustaka Utama, 2008.

Mahmud, Thahan. Taisir Musthalah Hadits. Riyadh: Maktabah Al-Ma'arif Lin-Nasyri Wat-Tauzi', 2010.

Miles, Matthew B., dan A. Michael Huberman. Analisis Data Kualitatif. Diterjemahkan oleh Tjetjep Rohendi. Jakarta: Penerbit Universitas Indonesia, 1992.

Moentaha, Salihen. Bahasa dan Terjemahan: Language and Translation. Bekasi: Kesaint Blanc, 2006.

Mukhtar. Metode Praktis Penelitian Deskriptif Kualitatif. Jakarta: GP Press Group, 2013.

Munawwir, Ahmad Warson. Al-Munawwir Kamus Arab-Indonesia. Surabaya: Pustaka Progressif, 1997.

Ni'mah, Fuad. Mulakhkhash Qawaidu Al-Lughati Al-Arabiyyah. Beirut: Daru AtsTsaqafah Al-Islamiyyah, 1988.

Nisak, Choirun. "Pergeseran Penerjemahan Dalam Novel Na'ib Izrail Karya Yusuf As-Siba'i." Universitas Sebelas Maret, 2019.

Rofiq, Aunur. Ringkasan Kaedah Bahasa Arab. Gresik: Yayasan Al-Furqon Al-Islami, 2018.

Sari, Nurul Intan, Nababan M.r, dan Djatmika Djatmika. "Analisis Perbandingan Teknik Penerjemahan Istilah Tabu Dalam Film The Wolf Of Wall Street Dan Dua Terjemahannya (Subtitle Resmi VCD Dan Amatir Dari Situs Subscene.Com) Serta Dampaknya Pada Kualitas Terjemahan.” PRASASTI: Journal of Linguistics 1, no. 1 (2016): 80-102. https://doi.org/10.20961/prasasti.v1i1.910.

Sayfudin, Nur. "Konsep Tazkiyatun Nafs Perspektif Al-Ghozali Dalam Pendidikan Akhlak." Skripsi, $\quad$ IAIN Metro, 2018. https://repository.metrouniv.ac.id/id/eprint/1673/.

Simatupang, Maurits D.S. Pengantar Teori Terjemahan. Jakarta: Dirjen Pendidikan Tinggi Dediknas, 2000.

Sugiyono. Metode Penelitian Kombinasi (Mix Methods). Bandung: Alfabeta, 2015.

Verhaar, J.M.W. Asas-Asas Linguistik Umum. Yogyakarta: Gadjah Mada University Press, 2016.

Yunus, Mahmud. Kamus Arab-Indonesia. Jakarta: PT. Hidakarya Agung, 1990. 